\title{
Effect of Cyclandelate on Mental Function and Cerebral Blood Flow in Elderly Patients
}

\author{
J. A. C. BALL,* M.D., B.SC., M.R.C.P.ED.; A. R. TAYLOR, $\dagger$ M.A., M.B., F.R.C.S.
}

Brit. med. 7., 1967, 3, 525-528

There is no demonstrable impairment in the ability of the cerebral blood vessels of elderly subjects to dilate in response to physiological stimuli (Lassen, 1959), but there is general agreement that chemical agents are relatively ineffective in producing such dilatation. Recently, however, reports have appeared that dilatation of cerebral vessels has occurred in response to cyclandelate (Eichhorn, 1965 ; Kuhn, 1965), and there is some uncontrolled evidence that cyclandelate produces an improvement in mental function in elderly patients (Drift, 1961 ; Ravina, 1963 ; Ward, 1964).

As the production of a substantial improvement in mental function in elderly patients would be of inestimable value, a controlled trial of cyclandelate has been made so that its effect on mental function and cerebral circulation in elderly patients could be investigated.

\section{Present Trial}

Selection of Patients.-From a population of approximately 200 patients in the long-stay wards of Wakehurst House, the Geriatric Unit of the Belfast City Hospital, 32 were selected whose disabilities were static and who were not so deaf, blind, or demented as to make the mental function tests used unsuitable. There were nine men (average age 75.6 years, range 57-98) and 23 women (average age 76.9 years, range 50-89).

Method.-The 32 patients were divided into two groups of 16 by randomly allocating to each either cyclandelate or placebo. Before the trial began one of us (J.A.C. B.) made a full clinical examination and carried out mental function tests on all the patients. Within 24 hours of the mental function tests mean cerebral circulation time was measured by the other of us (A.R.T.). The patients in group A were then given a 200-mg. tablet of cyclandelate and those in group B an inert tablet identical in size, shape, and colour four times daily for four months. Until the trial was completed only the hospital pharmacist knew which tablets contained cyclandelate.

Mental function tests and radiocirculograms were repeated after two months and again after four months.

\section{Mental Function Tests}

The tests used were chosen to illustrate as many aspects of mental function as possible. As most of the patients in the trial had considerable mental impairment only simple tests could be used. Each test consisted of a series of simple questions and a set of simple tasks, and took about 30 minutes to complete.

The questions were similar to those used by Isaacs and Walkey (1964) and determined spatial, temporal, and personal orientation. Short-term memory was assessed by the method of paired associates (Isaacs and Walkey, 1964). Constructional skill and spatial orientation were estimated by means of building blocks and a pegboard (Isaacs and Walkey, 1964 ; Adams and Hurwitz, 1963). To provide a measure of reason, imagina- tion, and verbal expressive ability, the patients were asked to differentiate between a pond and a stream and between a ladder and a staircase and to describe a series of picture absurdities (Terman and Merrill, 1955).

In the final part of the mental function test patients were asked the battery of questions described under the headings of clinical sensorium test (Part 1), clinical questionary, and memory questionary used in the Institute of Psychiatry at the Maudsley Hospital for assessment of mental function in elderly patients (Shapiro et al., 1956). These questions examined separately general orientation, memory for past personal events, memory for recent personal events, memory for general events, and ward orientation.

With the questions and the paired associates, one mark was given for each correct answer. In the tests with the building blocks and the pegboard, additional marks were given when assembly was completed quickly, and marks were deducted when demonstration or assistance was necessary or when the task was not finished within a set time.

Answers to the questions about differences and the responses to the picture absurdities were given up to five marks each, according to how close they came to predetermined levels of accuracy and appropriateness.

The scores obtained in the tests were dependent on the patient's alertness, concentration, and co-operation, but not on special skill, educational background, or social status.

\section{Cerebral Circulation Time}

The criterion adopted and thought to be the best simple indicator of blood flow was the mean circulation time (M.C.T.). This was obtained by the method described by Oldendorf (1963). In this, $50 \mu \mathrm{Ci}$ of ${ }^{131} \mathrm{I}$ Hippuran (iodohippurate) is rapidly injected to an antecubital vein and a stream or bolus of radioactivity approaches the head through the carotid and vertebral vessels after passage through the heart and lungs and holds together for one circulation through the cerebral blood pool. Its passage is detected by a collimated crystal directed through the inion towards a point 1 in. $(2.5 \mathrm{~cm}$.) above the nasion. Impulses are amplified and passed via a ratemeter to a pen-recorder. A typical curve of counts per second with time is seen in the upper part of Fig. 1. The height $\mathbf{P}$ (peak activity) is an indication of the flow rate, as are the angles of rise and fall of the curve. When the first order derivative of the activity curve is drawn, however, as in the lower part of Fig. 1, more accurate measurements can be made. This second curve shows the rate of change of activity with time and has positive and negative peaks indicating maximum rates of change in a positive and negative direction. These two points correspond to the passage of the dense central part of the bolus to and from the scanned area. The interval between the two points is the mean carotid-to-jugular time (M.C.T.). This is the time taken by the average blood cell to cross the cerebral blood pool, and varies in inverse ratio to the cerebral blood flow.

That there are many such times was shown by Nylin et al. (1960), who injected ${ }^{32} \mathrm{P}$-labelled red cells into the carotid 
artery and monitored the radioactive stream in both jugular veins by mechanical sampling once every second. The first cells arrived in 1-2 seconds, and the last in 12-15 seconds. The average M.C.T. found by Nylin et al. in a group of
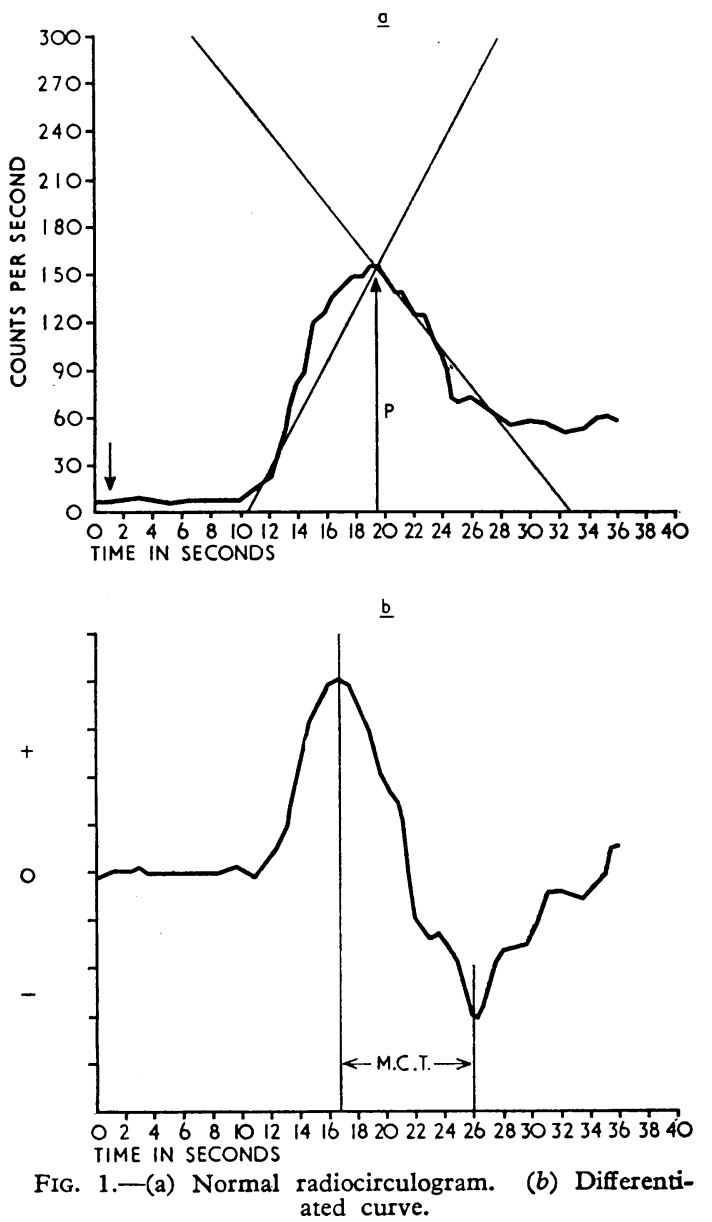

normal patients was 7.3 seconds (standard error 0.9 second). This closely corresponds to an average M.C.T. of 7.41 seconds (S.E. 0.1 second) found here in a group of normal patients whose mean age was 32 years (Taylor and Bell, 1966).

\section{Course of the Trial}

Three patients refused to take their tablets shortly after the trial began. Two of them were on cyclandelate and one on placebo. Four patients died during the course of the trial; one was on cyclandelate and three were on placebo. One patient on placebo was too ill at the end of the first trial period for mental function testing to be possible. Mental function tests were thus completed on three occasions on each of the remaining 24 patients, 13 of whom were on cyclandelate and 11 on placebo.

One patient who had completed four months' treatment with cyclandelate had a right cerebral thrombosis on the morning after her mental function test. The results of this test have been included in the analyses, but further cerebral circulation studies were not made. Another patient, also on cyclandelate, had a technically unsuccessful radiocirculogram, the results of which could not be analysed. Three successful radiocirculograms were thus performed on each of 22 patients, 11 of whom were on cyclandelate and 11 on placebo.

\section{Results}

In all the analyses a result is termed significant when the probability of its occurrence by chance is less than 0.05 .

Comparison of the ages of the patients in each of the two groups by use of a $t$ test showed that, on average, they were not significantly different. Calculation of exact probability showed that the distribution of males and females between the two groups of patients was random $(P$ (double tail $)=0.67918$ ). There was no significant difference between the average initial scores in the mental function tests or in average initial mean circulation times in the two groups.

The two groups of patients were therefore comparable initially.

\section{Mental Function Tests}

The analysis of the results of the mental function tests is set out in Table I. Analysis was made of the differences between the average initial scores and the average scores obtained after the first and the second treatment periods in each of the two groups, and the differences between the average scores on each occasion in the two groups. The scores obtained at the end of the first and the second periods were also compared with each other in order to show whether continuation of treatment for the second two months resulted in further significant change.

After the first two months group A patients obtained significantly higher average scores in the tests with the differences and picture absurdities (which were considered together), and with the pegboard. After four months significantly higher average scores were obtained in all the mental function tests except those with the paired associates and the building blocks.

TABLE I.-Analysis of Results of Mental Function Tests

\begin{tabular}{|c|c|c|c|c|c|c|c|c|c|c|c|c|}
\hline & & & \multirow{2}{*}{ Group } & \multicolumn{3}{|c|}{ Mean Test Score } & \multicolumn{3}{|c|}{ Mean Test Score Differences } & \multicolumn{3}{|c|}{ Standard Error of Mean Differences } \\
\hline & & & & $\mathbf{I}$ & II & III & I-II & II-III & I-III & I-II & II-III & I-III \\
\hline Questions .. & . & $\ldots$ & $\stackrel{\mathrm{A}}{\mathrm{B}}-\mathbf{B}$ & $\begin{array}{r}6.54 \\
6.91 \\
-0.37\end{array}$ & $\begin{array}{r}7.15 \\
7.00 \\
+0.15\end{array}$ & $\begin{array}{r}8.85 \\
627 \\
+2.58\end{array}$ & $\begin{array}{l}+0.61 \\
+0.09 \\
+0.52\end{array}$ & $\begin{array}{l}+1.70^{*} \\
-0.73 \\
+2.43^{*}\end{array}$ & $\begin{array}{l}+2.31^{*} \\
-0.64 \\
+2.95^{*}\end{array}$ & $\begin{array}{l}0.42 \\
0.48 \\
0.63\end{array}$ & $\begin{array}{l}0.38 \\
0.38 \\
0.54\end{array}$ & $\begin{array}{l}0.55 \\
0.65 \\
0.85\end{array}$ \\
\hline Paired associates & . & $\cdots\{$ & $\stackrel{\mathrm{A}}{\mathbf{B}-\mathbf{B}}$ & $\begin{array}{r}10.00 \\
9.55 \\
+0.45\end{array}$ & $\begin{array}{r}11.92 \\
10.82 \\
+1.10\end{array}$ & $\begin{array}{r}11.62 \\
10.82 \\
+0.80\end{array}$ & $\begin{array}{l}+1.92 \\
+1.27 \\
+0.65\end{array}$ & $\begin{array}{r}-0.30 \\
+0.00 \\
-0.30\end{array}$ & $\begin{array}{l}+1.62 \\
+1.27 \\
+0.35\end{array}$ & $\begin{array}{l}1.17 \\
0.98 \\
1.53\end{array}$ & $\begin{array}{l}0.73 \\
0.80 \\
1.08\end{array}$ & $\begin{array}{l}0.92 \\
1.11 \\
1.44\end{array}$ \\
\hline \multicolumn{3}{|c|}{ Differences and pictures } & $\stackrel{\mathrm{A}}{\mathrm{B}-\mathrm{B}}$ & $\begin{array}{r}14.62 \\
14.27 \\
+0.35\end{array}$ & $\begin{array}{r}17.85 \\
15.54 \\
+2.31\end{array}$ & $\begin{array}{r}19 \cdot 38 \\
16 \cdot 18 \\
+3 \cdot 20\end{array}$ & $\begin{array}{l}+3.23^{*} \\
+1.27 \\
+1.96\end{array}$ & $\begin{array}{l}+1.53 \\
+0.64 \\
+0.89\end{array}$ & $\begin{array}{l}+4.76^{*} \\
+1.91 \\
+2.85\end{array}$ & $\begin{array}{l}1.04 \\
1.85 \\
2 \cdot 12\end{array}$ & $\begin{array}{l}1 \cdot 15 \\
0.88 \\
1.45\end{array}$ & $\begin{array}{l}1 \cdot 33 \\
1 \cdot 72 \\
2 \cdot 17\end{array}$ \\
\hline Building blocks & - & $\cdots$ & $\stackrel{\stackrel{A}{B}}{A-B}$ & $\begin{array}{r}4 \cdot 15 \\
3 \cdot 18 \\
+0.97\end{array}$ & $\begin{array}{r}4.54 \\
3.55 \\
+0.99\end{array}$ & $\begin{array}{r}4.00 \\
3.91 \\
+0.09\end{array}$ & $\begin{array}{l}+0.39 \\
+0.37 \\
+0.02\end{array}$ & $\begin{array}{l}-0.54 \\
+0.36 \\
-0.90\end{array}$ & $\begin{array}{r}-0.15 \\
+0.73 \\
-0.88\end{array}$ & $\begin{array}{l}0.31 \\
0.38 \\
0.50\end{array}$ & $\begin{array}{l}0.35 \\
0.36 \\
0.51\end{array}$ & $\begin{array}{l}0.32 \\
0.51 \\
0.60\end{array}$ \\
\hline Pegboard ... & $\cdots$ & .. & $\stackrel{\mathrm{A}}{\mathbf{A}-\mathbf{B}}$ & $\begin{array}{r}5.85 \\
5.82 \\
+0.03\end{array}$ & $\begin{array}{r}6.92 \\
7.00 \\
-0.08\end{array}$ & $\begin{array}{r}7 \cdot 15 \\
6 \cdot 82 \\
+0.33\end{array}$ & $\begin{array}{l}+1.07^{*} \\
+1.18 \\
-0.11\end{array}$ & $\begin{array}{l}+0.23 \\
-0.18 \\
+0.41\end{array}$ & $\begin{array}{l}+1.30 * \\
+1.00 \\
+0.30\end{array}$ & $\begin{array}{l}0.49 \\
0.81 \\
0.94\end{array}$ & $\begin{array}{l}0.57 \\
0.60 \\
0.82\end{array}$ & $\begin{array}{l}0.44 \\
0.98 \\
1.08\end{array}$ \\
\hline Maudsley questio & & .. \{ & $\stackrel{\stackrel{A}{B}}{\mathbf{A}-\mathbf{B}}$ & $\begin{array}{r}24.31 \\
23.55 \\
+0.76\end{array}$ & $\begin{array}{r}24.38 \\
23.55 \\
+0.83\end{array}$ & $\begin{array}{r}30.46 \\
23.00 \\
+7.46\end{array}$ & $\begin{array}{l}+0.07 \\
+0.00 \\
+0.07\end{array}$ & $\begin{array}{l}+6.08^{*} \\
-0.55 \\
+6.63^{*}\end{array}$ & $\begin{array}{l}+6.15^{*} \\
-0.55 \\
+6.70^{*}\end{array}$ & $\begin{array}{l}1.05 \\
0.92 \\
1.40\end{array}$ & $\begin{array}{l}0.96 \\
0.85 \\
1.28\end{array}$ & $\begin{array}{l}1 \cdot 39 \\
1 \cdot 10 \\
1 \cdot 77\end{array}$ \\
\hline
\end{tabular}


Group B patients showed no significant improvement in the average scores obtained in any of the mental function tests at the end of either treatment period.

\section{Radiocirculograms}

The positive and negative peaks of the rate of change of activity curve can be precisely defined in normal records. Where the circulation is greatly slowed, however, as it was in most of the patients studied, the rate of change of activity as the bolus leaves the cerebral circulation is small and the negative peak may be blurred or double (Fig. 2). To define this peak

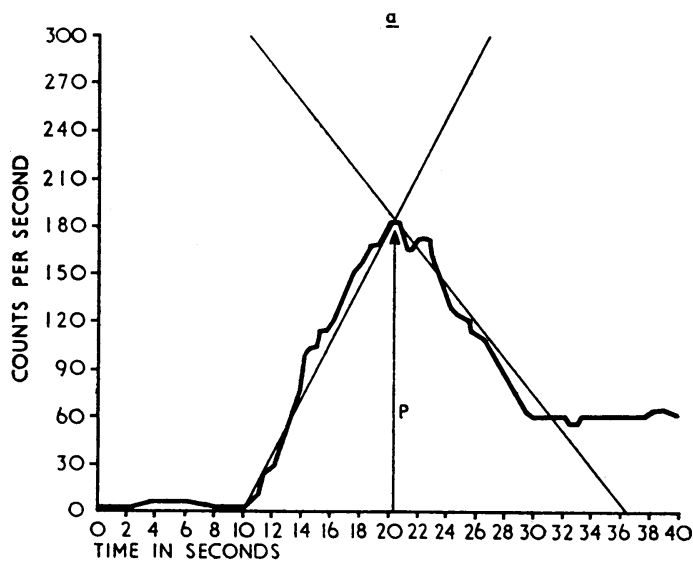

$\underline{b}$

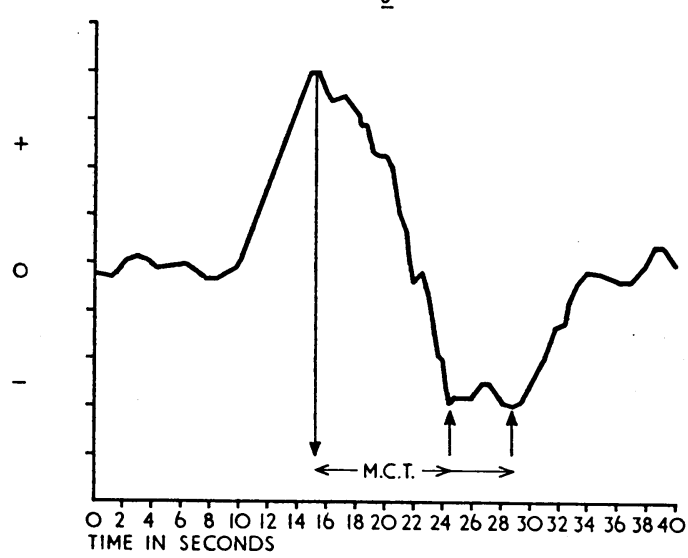

FIG. 2.-(a) Abnormal radiocirculogram. (b) Differentiated curve showing double negative peak.

the curve has to be artificially smoothed, and this introduces a possible error of one to two seconds. The curves were read by us, by a third doctor (not associated with the trial), and by an architect without medical knowledge. The architect's method of smoothing the curves differed slightly from ours and his mean circulation times, in doubtful cases, were consistently a little longer, but the results in terms of improvement or worsening were the same in all cases.

The analysis of the results of the radiocirculograms is set out in Table II. Over the four-month period the average mean circulation time in group A patients decreased by 0.86 second (S.E. 0.39 second), and in group $B$ patients there was an average increase of 0.55 second (S.E. 0.43 second). These average mean circulation-time changes are not significant. However, when the changes in group $\mathrm{A}$ are compared with those in group B, the average mean circulation-time difference 1.41 seconds ( S.E. 0.58 second), is significant.

\section{Correlation Between Mental Function Test Scores and Mean Circulation Times}

Absolute values of cerebral blood flow can be derived from mean circulation times when the constants of proportion are known (Oldendorf, 1963). These constants depend on total blood volume and the ratio of brain blood volume to total blood volume, and therefore vary greatly from patient to patient.

If it is assumed that mental function test scores are related to cerebral blood flow, the constants of proportion would again be expected to vary greatly from patient to patient.

Two different kinds of constant, both of unknown value, are thus involved in the relation between mental function test scores and mean circulation times. In order to test for a relation by use of the figures obtained in the present trial, it was necessary to derive an expression in which the unknown constants did not appear.

The relation between mean circulation time in seconds (m) and cerebral blood flow in litres per minute (c) is

$$
\mathrm{m}=\frac{\mathrm{K}}{\mathrm{c}}
$$

Where the constant $\mathrm{K}$ is dependent on total blood volume and the ratio of total blood volume to brain blood volume.

If mental function test score $(x)$ is proportional to cerebral blood flow, then $x=k c$.

So that

$$
\mathrm{m}=\frac{\mathrm{Kk}}{\mathrm{x}}
$$

As in any one patient $\mathrm{Kk}$ will be constant, $\mathrm{m}$ will vary inversely as $x$, and if $m$ and $x$ change then

$$
\mathrm{m}+\mathrm{dm}=\frac{\mathrm{Kk}}{\mathrm{x}+\mathrm{dx}}
$$

where $d m$ represents the change in $m$ and $d x$ represents the change in $x$.

Subtracting (I) from (II)

$$
\mathrm{dm}=\mathrm{Kk} \frac{-\mathrm{dx}}{\mathrm{x}(\mathrm{x}+\mathrm{dx})}
$$

and dividing by (I) to eliminate $\mathrm{Kk}$

$$
\mathrm{dm}=\frac{-\mathrm{mdx}}{\mathrm{x}+\mathrm{dx}}
$$

A significant positive correlation between $\mathrm{dm}$ and the expression $-\frac{\mathrm{mdx}}{\mathrm{x}+\mathrm{dx}}$ would support the hypothesis that mental function test scores vary with cerebral blood flow. Low correlation coefficients would suggest that the two are not related.

Correlation coefficients were calculated between changes in mean circulation time over the whole period of the trial and the changes in score in each separate section of the mental function tests as incorporated in the derived expression. In

\begin{tabular}{|c|c|c|c|c|c|c|c|c|c|c|c|}
\hline \multirow{2}{*}{\multicolumn{3}{|c|}{ Group }} & \multicolumn{3}{|c|}{ Average Mean Circulation Times } & \multicolumn{3}{|c|}{ Average Mean Circulation Time Differences } & \multicolumn{3}{|c|}{ Standard Error of Mean Differences } \\
\hline & & & I & II & III & I-II & II-III & I-III & I-II & II-III & I-III \\
\hline $\begin{array}{l}\mathbf{A} \\
\mathbf{A}\end{array}-\dot{B}$ & $\begin{array}{l}\cdots \\
\cdots\end{array}$ & $\begin{array}{l}\cdots \\
\cdots\end{array}$ & $\begin{array}{r}12.64 \\
12.14 \\
+0.50\end{array}$ & $\begin{array}{r}11.96 \\
12.36 \\
-0.40\end{array}$ & $\begin{array}{r}11.77 \\
12.68 \\
-0.91\end{array}$ & $\begin{array}{l}-0.68 \\
+0.23 \\
-0.91\end{array}$ & $\begin{array}{l}-0.18 \\
+0.32 \\
-0.50\end{array}$ & $\begin{array}{l}-0.86 \\
+0.55 \\
-1.41\end{array}$ & $\begin{array}{l}0.42 \\
0.39 \\
0.57\end{array}$ & $\begin{array}{l}0.54 \\
0.51 \\
0.74\end{array}$ & $\begin{array}{l}0.39 \\
0.43 \\
0.58\end{array}$ \\
\hline
\end{tabular}
the calculations a few results had to be neglected because the numerator or the denominator of the expression became zero. None of the correlation coefficients so calculated was significant.

TABLE II.-Analysis of Results of Radiocirculograms 


\section{Patients' and Ward Sisters' Opinions}

Four of the patients on cyclandelate and three of those on placebo thought that the tablets had done them good.

The ward sisters were asked to say if the tablets had had any effect on the patient's general mental state. They thought that there had been no change in 18 of the patients, that 4 patients on placebo and 2 on cyclandelate had improved, and that none was made worse.

An examination made of all the patients who remained on treatment until the end of the trial showed that there had been no change in their general clinical condition.

\section{Side-effects}

Only one patient complained of any ill effect from the tablets, saying that they made her dizzy. She was persuaded to continue taking tablets, which later turned out to be placebo.

\section{Discussion}

The improvement which occurred in mental function in group A patients was not expected, and yet in the tests with the questions and in those described by Shapiro et al. (1956) the increase in the scores was highly significant $(P<0.001)$.

The design of the trial ensured that bias on the part of the investigators, ward staff, or patients was removed; but the number of patients involved was small, and became smaller by the end of the four-month trial period. The assessment of improvement was made on the basis of an arbitrary scoring system, and the analysis of the score figures is made on the assumption that these are normally distributed. With such a small number of figures, however, it is not possible to validate or invalidate this assumption.

Nevertheless, as a significant improvement in mental function did occur in group A patients and not in group B patients, it must be concluded that the improvement was brought about by the action of cyclandelate.

The radiocirculogram results showed an average decrease in mean circulation time, indicating an average increase in cerebral blood flow only in group A patients. When the two groups were compared with each other the difference in the average mean circulation times over the four-month period was significant. It must be pointed out, however, that the change became significant only because group A showed a decrease in mean circulation time whereas group B showed an increase.

In patients with advanced arteriosclerosis, mean circulation times are prolonged and cerebral blood flow decreased (Nylin et al., 1960). Parallelism has been found between decreased mental function and reduced cerebral blood flow (Schmidt, 1950).

A change in mean circulation time indicates a proportional change in cerebral blood flow, so that should changes in mental function test scores result from changes in cerebral blood flow correlation between mean circulation time differences and the expression relating them to mental function test score differences would be expected, but no such correlation was found.

Eichhorn (1962), in a study of patients with hypertensive encephalopathy, made the interesting observation, from detailed analysis of the rising slope of his blood-flow curves, that the improvement which occurred was in the precapillary (arteriolar) phase of the circulation. He concluded that improvement was caused by a more efficient distribution of the available blood rather than to an increase in total flow.

The improvement in mental function brought about by the action of cyclandelate may similarly result from a redistribution of, rather than a total increase in, cerebral blood flow.

It has been suggested that the decrease in cerebral blood flow encountered in elderly patients involves preponderantly those areas in which perfusion normally is relatively high (Sokoloff, 1960). Even minor increases in flow to such relatively ischaemic areas might well result in their improved function.

\section{Summary}

A controlled clinical trial is described in which the effect of prolonged administration of cyclandelate on mental function and cerebral flow in elderly patients was tested. Group A patients were given cyclandelate and group B patients were given a placebo, each for a period of four months.

A significant improvement in the results of mental function tests occurred only in group A patients.

An increase in the average cerebral bbood flow occurred in group A patients and a decrease occurred in group B patients. Neither of these changes was itself significant, but when the two groups were compared with each other a significant difference occurred between them.

As there was no significant correlation between the changes in patients' scores in the mental function tests and changes in their mean circulation times, it is suggested that cyclandelate may bring about an improvement in mental function by producing a redistribution of blood flow within the cerebral circulation rather than an absolute increase in it.

We wish to thank Dr. J. D. Merrett for his help with the statistics ; Mrs. E. T. Hutchinson and Mr. J. Coulter, who dispensed the tablets; Mr. Richard Wall, of Messrs. Brocades (Great Britain) Ltd., for supplies of cyclandelate and placebo and for much helpful criticism; and Miss M. Carey and Miss E. Johnston who prepared the manuscript.

Details of the mental function tests and of the scoring system used, together with individual test scores, mean circulation times, and their correlation coefficients, can be obtained on application to J. A. C. Ball.

\section{REFERENCES}

Adams, G. F., and Hurwitz, L. J. (1963). Lancet, 2, 533.

Drift, J. H. A. van der (1961). Angiology, 12, 401 .

Eichorn, O. (1962). Medicamundi, 8, 76.

(1965). Vasc. Dis., 2, 305

Isaacs, B., and Walkey, F. A. (1964). Geront. Clin. (Basel), 6, 114.

Kuhn, R. A. (1965). "'The Effects of Cyclandelate Upon Cerebral Blood Flow in Patients with "Stroke." "American College of Angiology, July 1965 .

Lassen, N. A. (1959). Physiol. Rev., 39, 183.

Lassen, N. A.. (1959). Physiol. Rev., 39, 183 . S. (1960). Brain, 83, 293.

Oldendorf, W. H. (1963). Nucleonics, 21, No. 4, p. 87.

Ravina, A. (1963). Presse méd., 71, 727.

Schmidt, C. F. (1950). The Cerebral Circulation in Health and Disease. Springfield, Illinois.

Shapiro, M. B., Post, F., Löfving, B., and Inglis, J. (1956). 9. ment. Sci., $102,233$.

Sokoloff, L. (1960). In Handbook of Physiology, edited by J. Field,

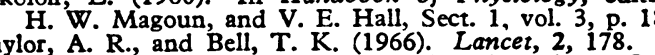

Taylor, A. R., and Bell, T. K. (1966). Lancet, 2, 178. Card Material for Revised Stanford-Binet Tests, Form M, Picture Absurdities. London.

Ward, P. J. (1964). Med. Dig. (Lond.), 9, 525. 